\title{
Unsaturated railway track-bed materials
}

\author{
Yu-Jun Cui \\ Ecole des Ponts ParisTech, U.R. Navier/CERMES, 6 - 8 av. Blaise Pascal, Cité Descartes, Champs - sur - Marne, 77455 Marne - la - \\ Vallée cedex 2, France
}

\begin{abstract}
Railway track-bed materials are mostly in unsaturated state, and their hydro-mechanical properties depend strongly on their water contents or suctions. In France, problematic soils such as collapsible loess and swelling marl can be origin of instability problems for new lines for high speed trains, while the hydro-mechanical behaviour of interlayer soil formed mainly by interpenetration of ballast and subgrade soil is of concern for conventional lines. In the latter case, the main challenge relies in the large variability of the interlayer soils owing to the variability of natural subgrade soils involved in the railway network. In this paper, a study on interlayer soils is presented, that covers a large spectrum of aspects: geotechnical/geophysical site characterisation, laboratory investigation into the hydraulic behaviour and mechanical behaviour as well as the mud pumping/interlayer creation phenomena, and field monitoring. The combined effect of water content and fines content were emphasized in the laboratory investigation, whilst interaction between atmosphere and track was focused on in the field monitoring. The results show clearly that it is of paramount importance to consider the unsaturated aspect of track-bed materials when analysing the overall behaviour of tracks, in particular when clay is involved in fine fraction.
\end{abstract}

\section{Introduction}

In France, most railway tracks are ballasted and the whole network is composed of new lines for high speed trains and conventional lines for other categories. In the case of new lines, a sub-layer of gravel is placed between ballast and subgrade, and sometimes a capping layer is put with treated soil between the sub-layer and subgrade (see Figure 1). This design has been proven to be successful when dealing with sub-grades of "noble soils". But when special soils such as expansive soils and collapsible soils are involved, additional measures should be taken in order to ensure the stability of tracks under the combined effect of water infiltration and cyclic loading. Indeed, in the case of northern line (Paris Lille), a subgrade of loess is involved. Under the effects of rainfall and dynamic loading, track instability problems were identified, leading to an extensive study to identify the main instability mechanisms (collapse upon wetting, fatigue under large number of loading cycles and liquefaction in the saturated sate) [1-6]. In the case of Mediterranean Line (Paris - Marseille), a subgrade of marl was encountered and its swelling due to the coupled effect of water infiltration and excavation-related unloading was revealed to be one of the main mechanisms for the significant track heave identified [7].

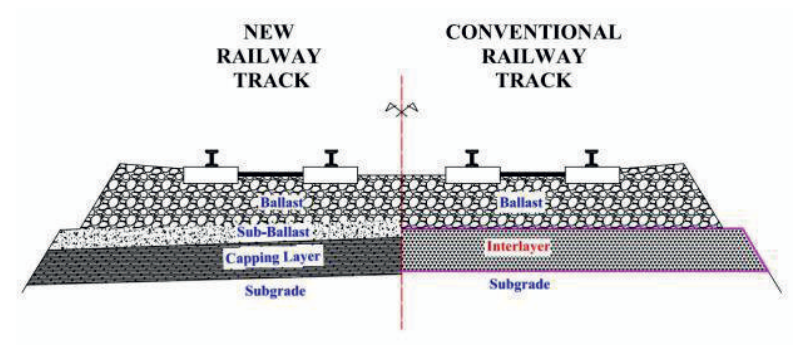

Figure 1. Comparison between new and conventional railway tracks.

As opposed to the new lines, the conventional lines have their ballast directly placed on the subgrade during their construction. Under the effect of train circulation over time, an interlayer was created mainly by the interpenetration of ballast and subgrade soils (see Figure 1). This layer is found to be well "compacted" by train circulation over long time: the in-situ dry density can be as high as $2.4 \mathrm{Mg} / \mathrm{m}^{3}$ [8]. Thereby, it constitutes a good bearing layer in the sub-structure. This is why it has been decided to keep this layer in the French program of conventional track renewal. Note that this track renewal program is important because it almost involves the whole French network: the conventional lines represent $94 \%$ of the whole network of about $30000 \mathrm{~km}$ [9]. Figure 2 shows a picture of soil profile taken when during sampling at the site of Sénissiat, France, after removing the ballast layer. An interlayer composed of coarse grains 
and fine particles can be clearly identified. When approaching the subgrade layer, the fraction of coarse grains seems to decrease, so that a transition layer can be defined that differentiated from interlayer by a lower coarse grain fraction.

Figure 3 shows a comparison of grain size distribution between sub-ballast and the interlayer soil taken at the site of Sénissiat. It appears that the main difference between the sub-ballast and the interlayer soil lies in the fines content: there is no grain smaller than $0.1 \mathrm{~mm}$ in sub-ballast whereas the fraction of grains smaller than $0.1 \mathrm{~mm}$ can reach $20 \%$ in the interlayer soil. Due to the presence of fines in the interlayer, the hydro-mechanical behaviour of the interlayer soil can be greatly affected by the sensitivity of the fines to changes in water content. Furthermore, as the nature and the amount of fines can be quite different from one site to another, the variability of materials constituting the interlayer is also an important issue to be addressed.

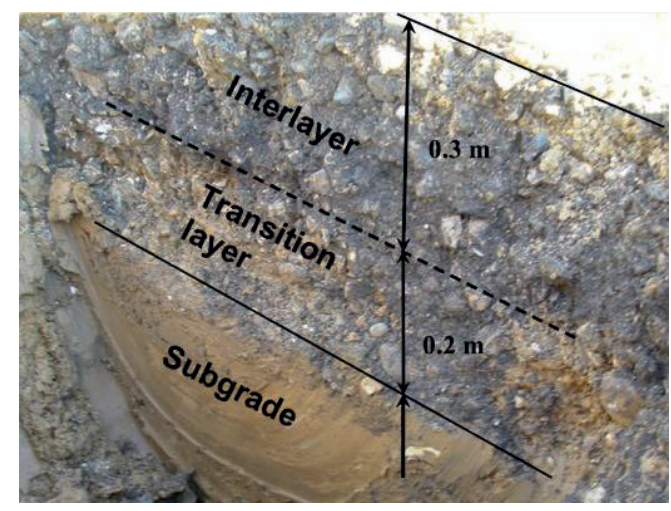

Figure 2. Interlayer at the site of Sénissiat.

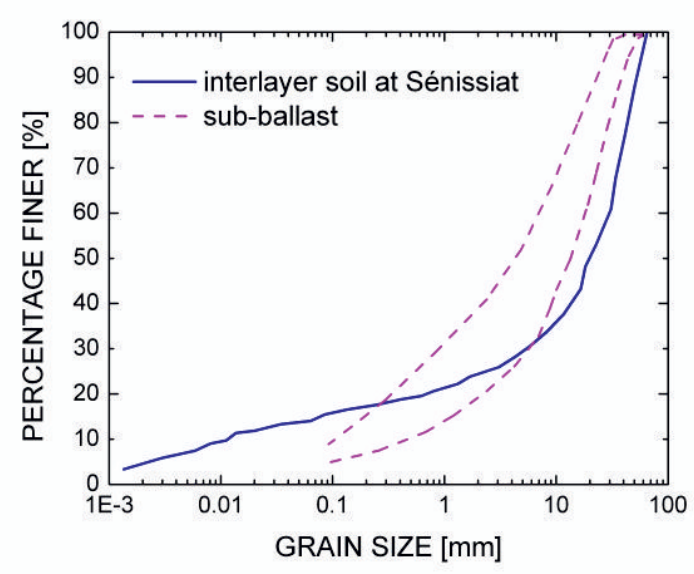

Figure 3. Comparison of grain size distribution between subballast and interlayer soil.

In this paper, the hydro-mechanical behaviour of interlayer materials is addressed through laboratory testing, physical modelling and field monitoring. A large scale infiltration cell equipped with tensiometer and TDR was developed to study the unsaturated hydraulic behaviour, and a large scale triaxial cell was employed to investigate the effects of water content and fines content under cyclic loading conditions. A physical model was developed to study the interlayer creation and the mud pumping phenomena. The field monitoring was conducted to investigate the interaction between the atmosphere and track.

\section{Site selection and prospection}

A site on a conventional line was needed to conduct the study on the hydro-mechanical behaviour of interlayer materials. To make the site representative, different criteria should be applied. For instance, for the selection of Vierzon site [10], it was imposed that the track components as rail and sleepers should not have more than ten years since their last renewal. In addition, the maximum service speed should be comprised between 200 and $220 \mathrm{~km} / \mathrm{h}$. A site with tracks in an alignment was also required to obtain the same solicitation at each side of each track. After selection of the site, geophysical and geotechnical prospections were conducted in order to investigate the site characteristics such as the Rayleigh wave velocity that is related to the critical velocity of train and the profile of soils of different geotechnical properties.

Different geophysical and geotechnical methods have been used in railway auscultations. The commonly used geophysical techniques are the multichannel analysis of surface waves (MASW), the ground penetrating radar or down-hole tests. MASW is used to analyse the propagation wave velocities in soil and the thicknesses of different layers of soil [11]. Ground penetrating radar (GPR) defines the thicknesses of different layers of substructure [12-13]. Down-hole seismic test is suitable for estimating the shear wave velocities of different trackbed materials [14]. On the other hand, most of the geophysical methods present some difficulties in trackbed investigations. For instance, the MASW is not easy to apply on track surface with ballast because common geophone pins are not adapted to be installed into large grains as ballast due to contact failure. Other geophysical methods, as GPR, are more suitable for qualitative auscultation of track-bed layers and for estimation of the thicknesses of track layers. For the geotechnical techniques, the mostly used ones are the dynamic penetration test (as PANDA tests) and the dynamic plate loading test (as the light weight deflectometer, LWD) [15-16]. They can help define the quality of a track-bed and the required thickness for different layers. The LWD test estimates the dynamic modulus of a soil, and is used for quality control. The PANDA test now becomes a common technique in France [17] since it allows prospecting the stiffness of existing tracks. The PANDA test measures the tip resistance of different materials. The elastic modulus of materials can be further estimated from their tip resistances using empirical equations.

The geo-endoscopic test uses a little video camera (wired to a data logger with a soft cable) to observe the soil. The camera is introduced into the hole of a previously performed PANDA test (15 mm of diameter). The results allow a qualitative characterization of soil, and even the estimation of the soil grain size distribution. 
The geo-endoscopic test is largely employed test in track prospections since the images and video obtained from this test allow the determination of different materials constituting the investigated soil layers: the thickness, the soil nature and even the state of saturation. This information can help better analyse the PANDA test results. In practice, PANDA and geo-endoscopic tests are often coupled for a same auscultation point.

Figure 4 shows the situations of prospection tests at the Vierzon site. Figure 5 shows different materials observed by geo-endoscope and Figure 6 gives an example of PANDA test results [10].

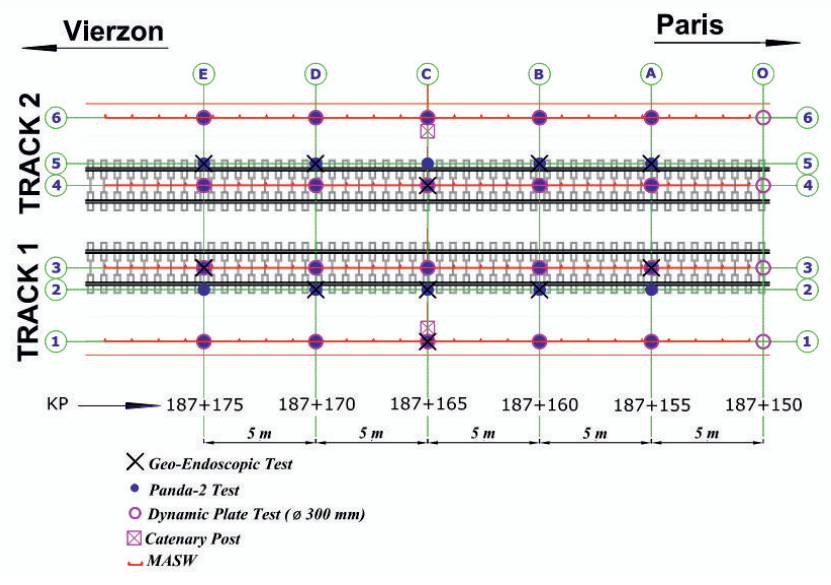

Figure 4. Prospection tests performed on the 'Vierzon experimental site'.

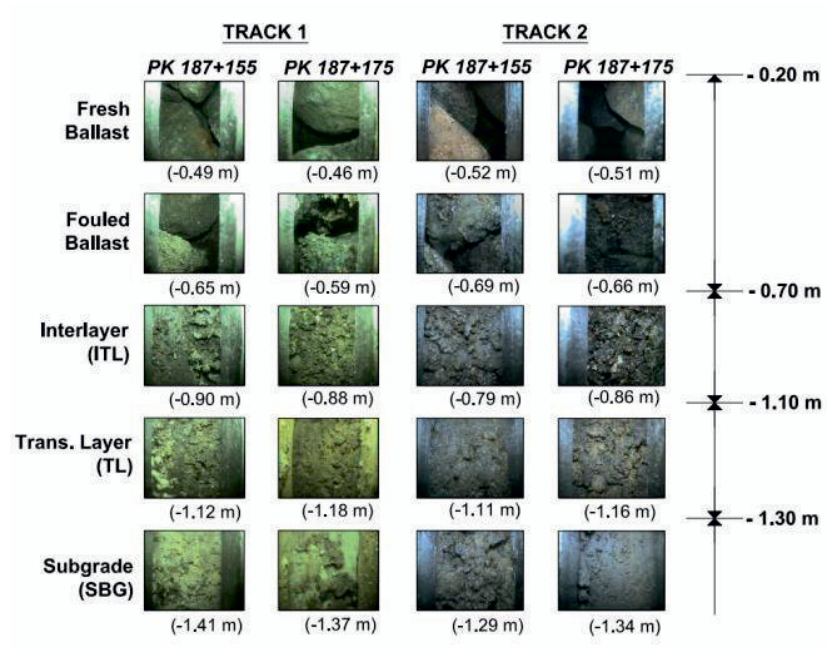

Figure 5. Different materials observed by Geo-endoscopic tests.

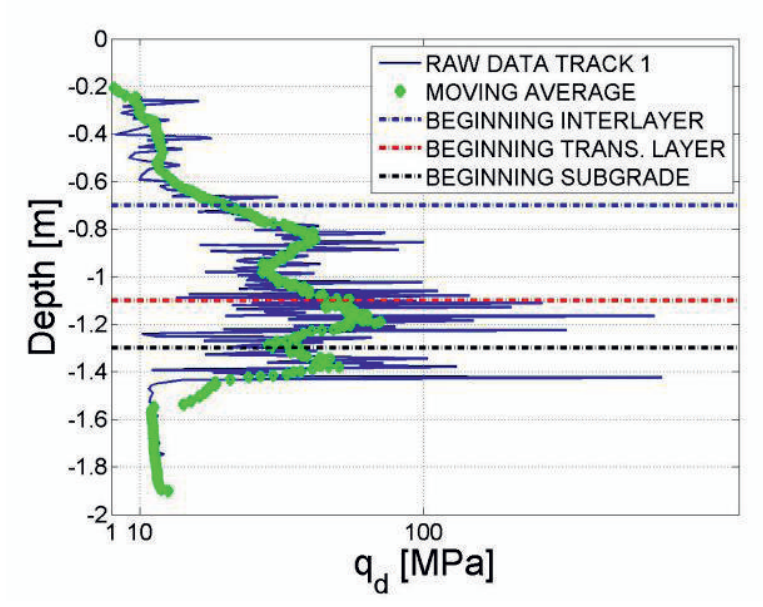

Figure 6. PANDA test result on track 1 and moving average (of 8 records).

All the test results allow the soil profile at Vierzon site to be well defined (see Figure 7), with $50 \mathrm{~cm}$ ballast (fresh and fouled), $40 \mathrm{~cm}$ interlayer (ITL), about $20 \mathrm{~cm}$ transition layer (TL) overlying the SBG. The water table is at $1.20 \mathrm{~m}$ depth from the rail level, near the interface between TL and SBG. Thus, the interlayer material is expected to be unsaturated.

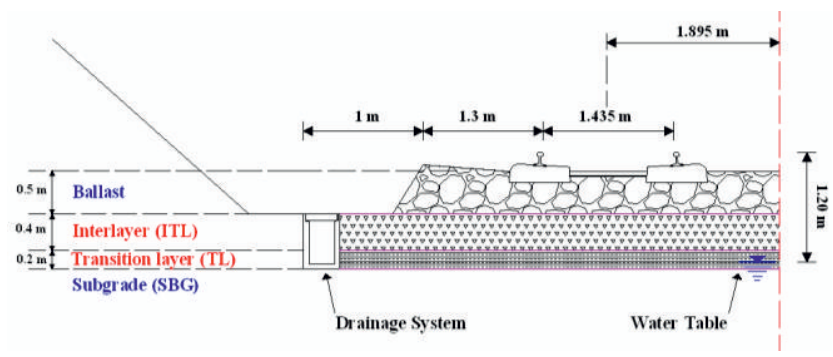

Figure 7. Profile of Vierzon site defined by the prospection tests.

\section{Laboratory investigation}

The laboratory investigation results are presented in three parts: i) hydraulic behaviour of interlayer soil, ii) mechanical behaviour of interlayer soil, and iii) physical modelling of the interlayer creation and mud pumping phenomena. Emphasis was put on the role of suction generated in the part of fine particles in the global hydraulic behaviour, while the roles of both suction/water content and fines content were stressed for the overall mechanical behaviour.

\subsection{Hydraulic behaviour}

The effect of fines content on the hydraulic behavior of interlayer soil was studied through the comparison between the fines $(<2 \mathrm{~mm})$ and $\mathrm{ITL}_{10}$ that is an interlayer soil with addition of a quantity of sub-grade representing $10 \%$ interlayer soil by dry mass [18]. 
The fines content was determined using a small-scale infiltration column of $50 \mathrm{~mm}$ in diameter and $200 \mathrm{~mm}$ in height, while ITL $_{10}$ was tested in a large-scale infiltration column $(300 \mathrm{~mm}$ in diameter and $600 \mathrm{~mm}$ in height) equipped with five TDRs for measuring water content and five tensiometers for measuring pore-water pressure [19]. The dry unit mass and water content of fines were taken equal to those of the fine particles contained in the sample of interlayer soil. Unlike the large-scale column where both suction and water content were monitored, the small-scale column has only suction monitored. To obtain the water content changes during infiltration, the soil-water retention curve (SWRC) was needed. This was done separately using an oedometer cell equipped with a high-capacity tensiometer (see Le et al. [20] for more details).

The instantaneous profile method [21-25] was applied for the determination of hydraulic conductivity for each soil. Note that this method is based on the generalized Darcy's law. The hydraulic gradient is determined by considering the slope of suction isochrones and the water volume passing through a given section between times $t$ and $t+\mathrm{d} t$ is used for calculating the water flux.

Figure 8 depicts the comparison of SWRC between ITL $_{10}$ and fines. The curves of the two soils start from almost the same point - around 97\% degree of saturation and $1.7 \mathrm{kPa}$ suction. Two drying curves were determined for fines, while one drying curve and two wetting curves were determined for $\mathrm{ITL}_{10}$. It is observed that the two drying curves of $\mathrm{ITL}_{10}$ are almost the same, so are the two wetting curves of fines, suggesting a good repeatability of the tests. A limited hysteresis was also identified for fines. Moreover, from $3 \mathrm{kPa}$ suction, the curves of fines start to separate from those of $\mathrm{ITL}_{10}$. The curves of drying path for the two soils are almost parallel from $10 \mathrm{kPa}$ suction. The curves of ITL $_{10}$ stop at $71 \mathrm{kPa}$ while the curves of fines stop at $389 \mathrm{kPa}$ due to the different capacities of the tensiometers used for the two soils. The gap between two curves is about $10 \%$ degree of saturation at the end of the curves for $\mathrm{ITL}_{10}$.

In Figure 9, the hydraulic conductivity of $\mathrm{ITL}_{10}$ and fines is plotted versus suction, together with the fitting curves using van Genuchten's and Brook-Corey's models. It can be observed that in unsaturated state the wetting and drying curves of the interlayer soil are quite close to those of fines, suggesting that the hydraulic conductivity of the interlayer soil is mainly governed by the hydraulic conductivity of the fines contained in it. In other words, in unsaturated state, water transfer in the interlayer soil takes place mainly through the network of pores between fine particles, coarse elements like ballast behaving as inert materials. By contrast, in saturated state, a value of $1.67 \times 10^{-5} \mathrm{~m} / \mathrm{s}$ was obtained for ITL $_{10}$, higher than the value for fines $\left(2.6 \times 10^{-6} \mathrm{~m} / \mathrm{s}\right)$. This difference is considered as being significant because as opposed to the determination of unsaturated hydraulic conductivity, the determination of saturated hydraulic conductivity can be deemed accurate. The higher value for ITL $_{10}$ can be explained as follows: the macro-pores in $\mathrm{ITL}_{10}$ are larger than those in fines and water flow in saturated state took place mainly through macro-pores.
Thereby, the water flow mechanism in saturated state is different from that in unsaturated state.

From a practical point of view, Figure 9 shows that when determining the unsaturated hydraulic conductivity of interlayer soils, it is not necessary to use large-scale experimental devices to match the soil grain size; smaller devices can be used to determine their hydraulic conductivity by testing the fine particles only, provided that equivalent dry density is accounted for. This is however not valid for saturated state.

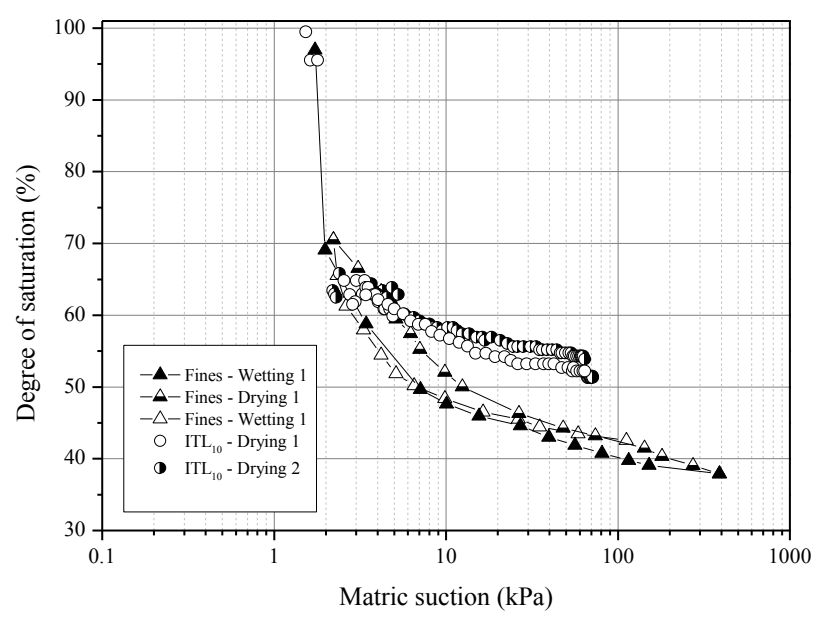

Figure 8. Comparison of SWRC between $\mathrm{ITL}_{10}$ and fines.

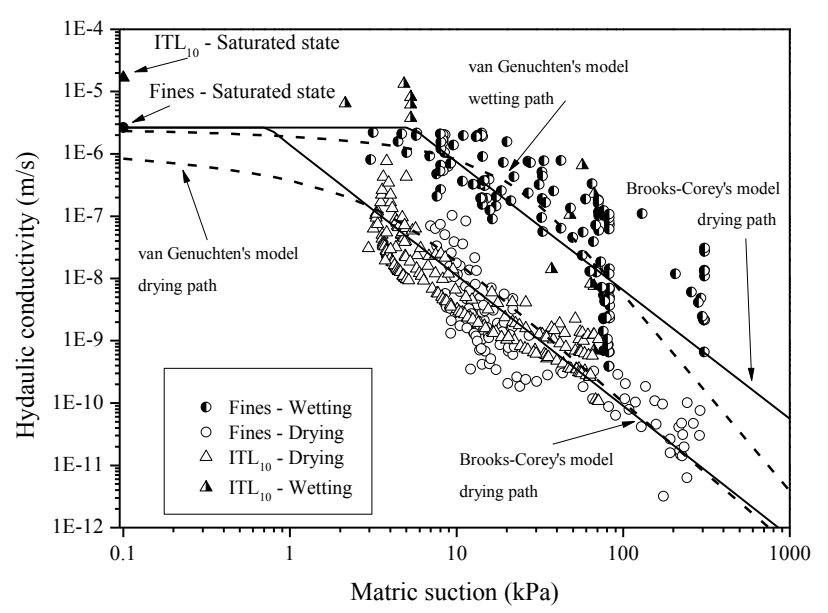

Figure 9. Comparison of hydraulic conductivity between $\mathrm{ITL}_{10}$ and fines.

On the other hand, Figure 9 also shows an uncommon phenomenon of hysteresis in hydraulic conductivity for $\mathrm{ITL}_{10}$ and fines. Indeed, it is observed that the curve of wetting path lies above the curve of drying path. The same phenomenon was observed by Wayllace and $\mathrm{Lu}$ [26]. The following interpretations can be attempted. Due to the different kinetic between the fast liquid transfer in wetting and the long vapour transfer in drying, the time needed for drying was much longer than that for wetting. This phenomenon was also reported by Toker et al. [27] and discussed by Munoz-Castelblanco et al. [5]. A higher hydraulic conductivity can be expected in that case for wetting path. In this study, the calculation of hydraulic conductivity was performed based on the suction evolution given by tensiometers. Assuming that 
in the compacted soils, both macro-pores and micro-pores exist. During wetting, the macro-pores were filled with water more quickly than micro-pores. Moreover, in the micro-pores, there were always air bubbles preventing the total saturation. By contrast, during drying, all pores (micro and macro) participated in the evaporation process. As a result, when water filled the macro-pores, the tensiometers immediately gave the suction changes corresponding to the water flow through the macro-pores, even though the suction in micro-pores would be higher. On the contrary, when water evaporates during drying, the tensiometers gave the suction changes that involve both macro- and micro-pores, in a much slower fashion. In other words, the suction measured by the tensiometers was probably under-estimated for wetting paths. Côté and Roy [28] also reported that one re-saturating stage is not enough to fully saturate a soil sample because of the air bubbles trapped in micro-pores. This can also explain the uncommon hysteresis mentioned before.

\subsection{Mechanical behaviour}

The mechanical behaviour has been investigated using a large scale cyclic triaxial cell that can host a sample of $300 \mathrm{~mm}$ diameter and $600 \mathrm{~mm}$ height [29]. Emphasis was put on the effects of water content and fines content on the resilient modulus and permanent deformation [30]. Based on the experimental results, a constitutive model was developed, taking into account both the effect of stress level and the effect of degree of saturation [9].

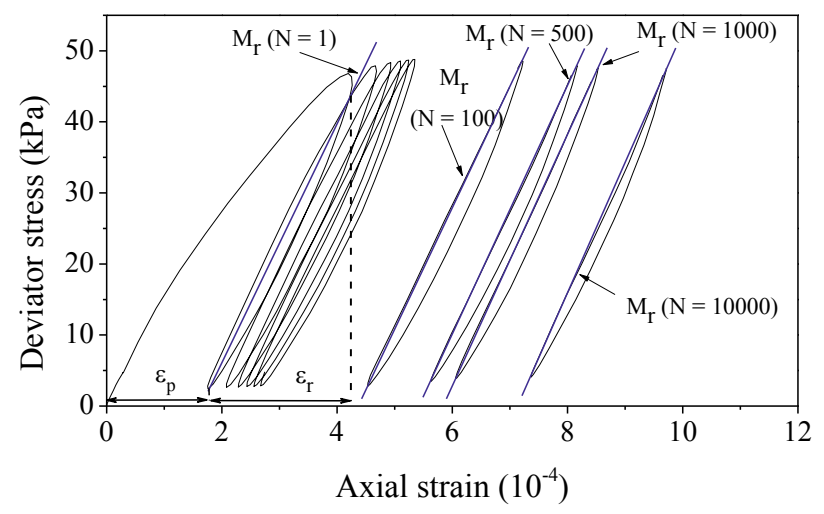

Figure 10. Deviator stress versus axial strain for test ITL5w6 Determination of resilient modulus.

Figure 10 presents typical curves of deviator stress versus axial strain for the first cycles in a test on the interlayer soil with addition of 5\% subgrade soil and at $6 \%$ water content - ITL5w6 [31]. It also shows the definition of permanent axial strain $\left(\varepsilon_{p}\right)$, the resilient axial strain $\left(\varepsilon_{r}\right)$ through the first cycle. The resilient modulus $\left(M_{r}\right)$ corresponds to the secant slope of curves (see Figure 10).

Three water contents $(4 \%, 6 \%$ and $12 \%)$ and four fines contents were considered ( $0 \%$ - natural ITL soil $\mathrm{ITL}_{0}, 5 \%$ - addition of 5\% subgrade soil $\mathrm{ITL}_{5}, 10 \%$ - addition of $10 \%$ subgrade soil ITL $_{10}$, as well as $-10 \%$ - removal of $10 \%$ fines from the natural ITL soil ITL $_{-10}$ ). Note that the water content of $12 \%$ corresponds to the saturated state, and only one test was carried out on the soil with $5 \%$ fine addition. The end-level resilient modulus values (after 30 000 cycles for each deviator stress level) are plotted versus deviator stress in Figure 11 for $\mathrm{ITL}_{10}, \mathrm{ITL}_{0}$ and ITL $_{-10}$. The value of ITL $_{-10}$ at $4 \%$ water content is the highest; the values of $12 \%$ water content are lower than those of $4 \%$ water content but higher than those of $6 \%$ water content. The relative positions of these curves show that the water content effect is not the same for the three materials. It appears that the increase of water content brings a negative effect to the resilient modulus of the soil that has the highest fines content $\left(\mathrm{ITL}_{10}\right)$. However, for $\mathrm{ITL}_{0}$ and $\mathrm{ITL}_{-10}$, the resilient modulus decreased when water content changed from $4 \%$ to $6 \%$ but increased when water content was increased to $12 \%$. Note that only a decreasing trend of resilient modulus with growing saturation level for granular material was observed by Lekarp at al. [32]. More studies are required to clarify this issue.

Figure 12 presents the results according to the water content: 4\% (Figure 12a), 6\% (Figure 12b) and 12\% (Figure 12a). The effect of fines content can be observed clearly. In the case of $w=4 \%$, the results of ITL $_{-10}$ and ITL $_{10}$ are almost identical for the deviator stress up to $100 \mathrm{kPa}$. But much lower values are observed for $\mathrm{ITL}_{0}$ for the deviator stress up to $140 \mathrm{kPa}$. Beyond $140 \mathrm{kPa}$ deviator stress, the values become almost the same for $\mathrm{ITL}_{-10}$ and $\mathrm{ITL}_{0}$. At $6 \%$ water content, the resilient modulus of $\mathrm{ITL}_{0}$ is also the smallest, showing that when decreasing the fines content (from $\mathrm{ITL}_{10}$ to $\mathrm{ITL}_{0}$ ), a reduction of resilient modulus is produced. However, when the fines content is decreased to a level as low as ITL $_{-10}$, the resilient modulus starts to increase. Under the saturation conditions $(w=12 \%$ in Figure $12 \mathrm{c})$, it is observed that the greater the fines content, the lower the resilient modulus. 

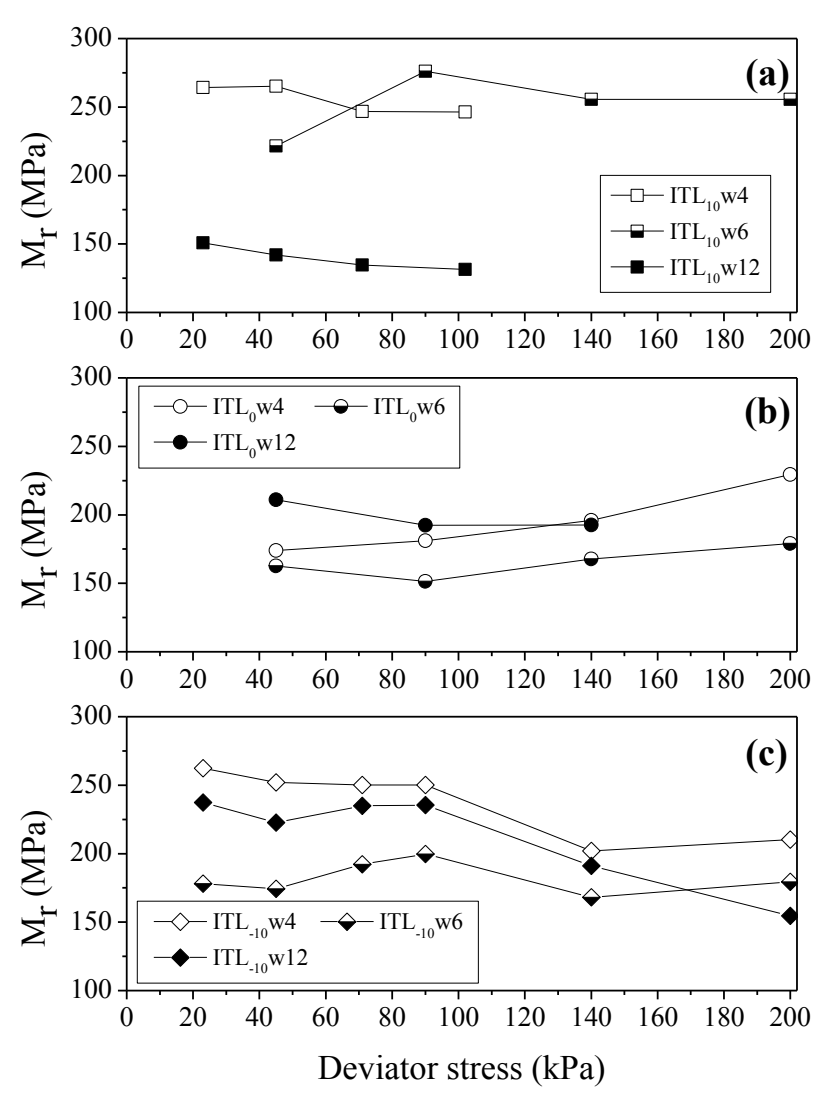

Figure 11. End-stage resilient modulus versus deviator stress Effect of water content. a) ITL 10 ; b) $\mathrm{ITL}_{0}$; c) ITL -10 .
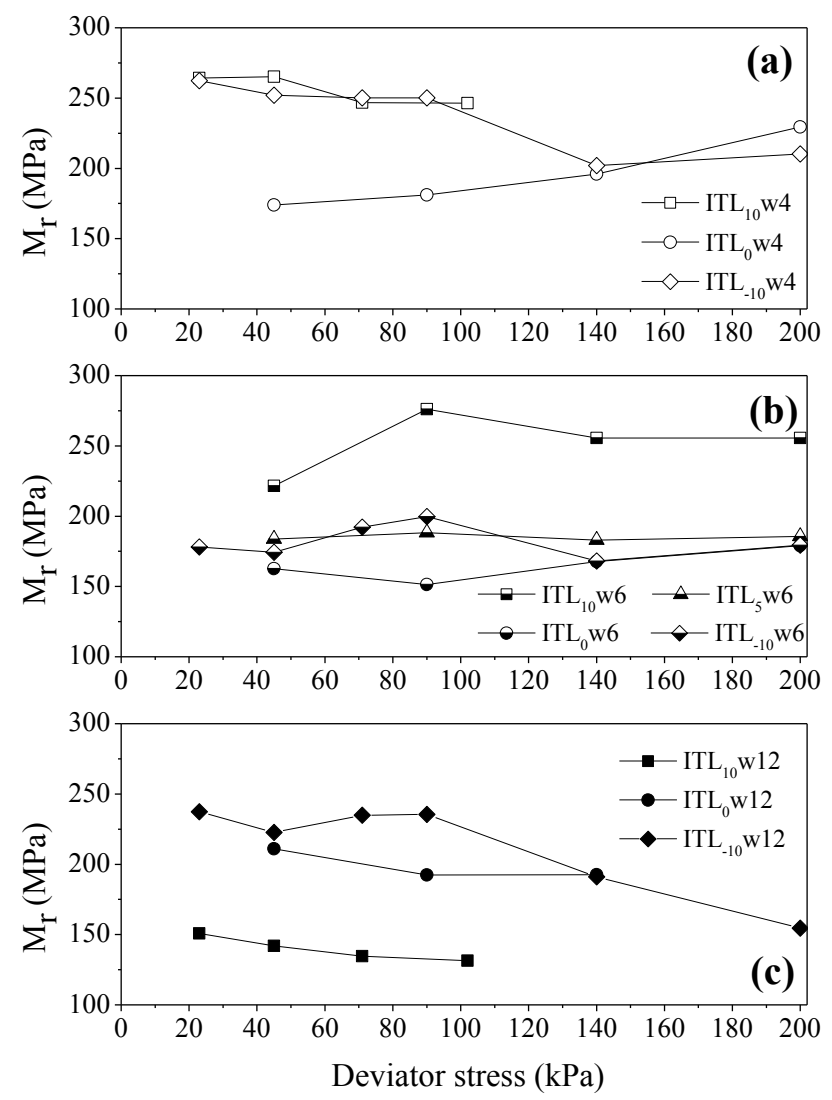

Figure 12. End-stage resilient modulus versus deviator stress Effect of fines content. a) $w=4 \%$; b) $w=6 \%$ and c) $w=12 \%$.
Figure 13 presents the permanent axial strains obtained at the end of each loading step (same number of cycles) versus the corresponding maximum deviator stress $\Delta q_{\max }$ for each soil at three different water contents, allowing analyzing the effects of stress level and water content on the permanent axial strain. For ITL $_{-10}$ (Figure 13a), the curves are similar up to $90 \mathrm{kPa}$ deviator stress. Beyond $90 \mathrm{kPa}$, the permanent axial strain of $\mathrm{ITL}_{-10} \mathrm{~W} 4 \mathrm{C}$ is smaller than those of ITL $\mathrm{IL}_{-10} \mathrm{~W} 6 \mathrm{C}$ and $\mathrm{ITL}_{-10} \mathrm{~W} 12 \mathrm{C}$. Note that failure occurred for the nearly saturated specimen $(w$ $=12 \%$ ) when $\Delta q_{\max }=200 \mathrm{kPa}$. For $\mathrm{ITL}_{0}$ (Figure 13b), three curves are well separated. At all stress levels, the higher the water content, the larger the permanent axial strain. Failure was also observed for the nearly saturated specimen at $\Delta q_{\max }=200 \mathrm{kPa}$. For $\mathrm{ITL}_{10}$ (Figure 13c), the curve of the specimens at $w=4$ and $6 \%$ are similar, while for the nearly saturated specimen ( $\left.\mathrm{ITL}_{10} \mathrm{~W} 12 \mathrm{C}\right)$, the permanent axial strain is much larger. The effect of water content depends not only on the soil nature but also on the variation range of water content. Changing water content from $4 \%$ to $6 \%$ does not significantly affect the permanent axial strain of $\mathrm{ITL}_{10}$ but induces significant changes in the case of lower fines content $\left(\mathrm{ITL}_{-10}\right.$ and $\mathrm{ITL}_{0}$ ). On the contrary, increasing water content from $6 \%$ to $12 \%$ induces a significant change in the permanent axial strain for $\mathrm{ITL}_{10}$, but not for $\mathrm{ITL}_{-10}$ when the stress is lower than $140 \mathrm{kPa}$. At a given stress level, increasing water content results in an increase in permanent axial strain.

Figure 14 shows the permanent axial strains obtained at the end of each loading step versus the corresponding $\mathrm{q}_{\max }$ for each water content value, allowing analyzing the effect of fines content on the permanent axial strain. In the case of $w=4 \%$ and $6 \%$ (Figures 14a and $14 \mathrm{~b}$, respectively), the permanent axial strains of $\mathrm{ITL}_{-10} \mathrm{~W} 4 \mathrm{C}$ and ITL $_{-10} \mathrm{~W} 6 \mathrm{C}$ are significantly higher than the others, suggesting that the lower the fines content, the larger the permanent axial strain. In nearly saturated state (Figure 14c), the effect of fines content is inversed: the soil having the highest fines content $\left(\mathrm{ITL}_{10}\right)$ exhibits the largest permanent axial strain [30]. Uthus et al. [33] also observed that the effect of water content on the permanent axial strain depends on the fines content. This phenomenon can be explained as follows: in unsaturated state, water is mainly trapped by fine particles. At the same density and water content, if the fines content is higher, the soil suction must be higher. As a result, the soil is mechanically more resistant. On the other hand, fine particles are well known to be very sensitive to changes in water content, and when the water content is $12 \%$, the soil becomes saturated and its suction approaches zero, leading to a significant decrease in fine particles strength and further the overall mechanical behavior of soil. Similar observations were reported by Fortunato et al. [34], Seif El Dine et al. [35] and Huang et al. [36]. 

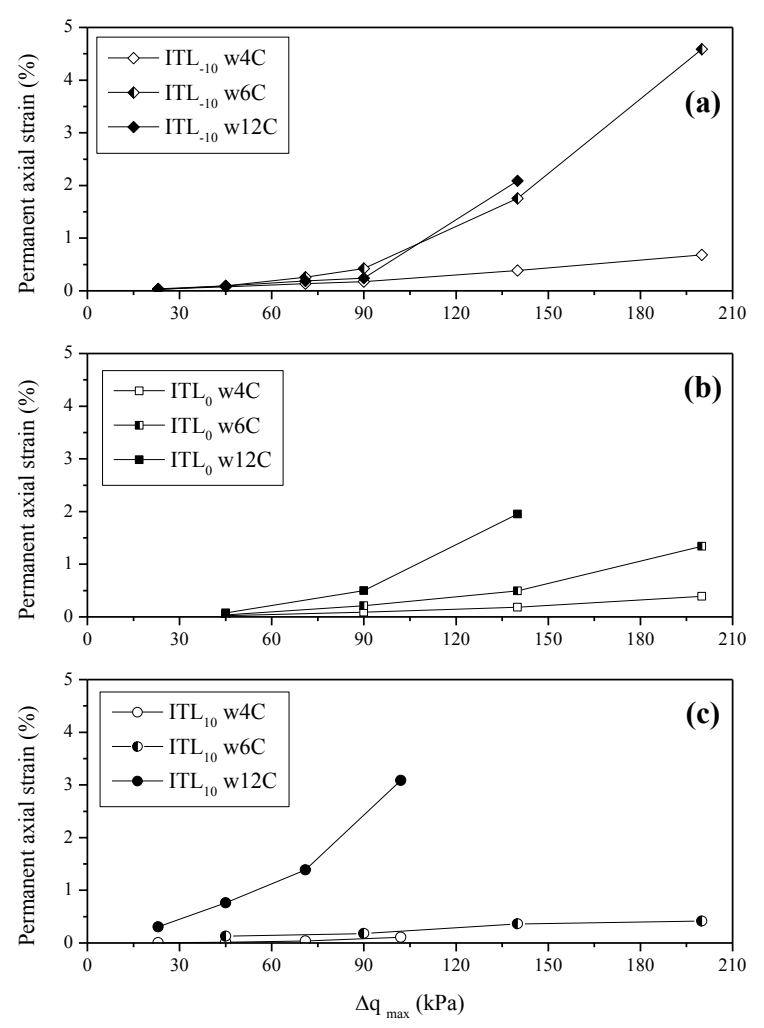

Figure 13. Effect of water content on the end-stage permanent axial strain for $\mathrm{ITL}_{-10}, \mathrm{ITL}_{0}$ and $\mathrm{ITL}_{10}$.
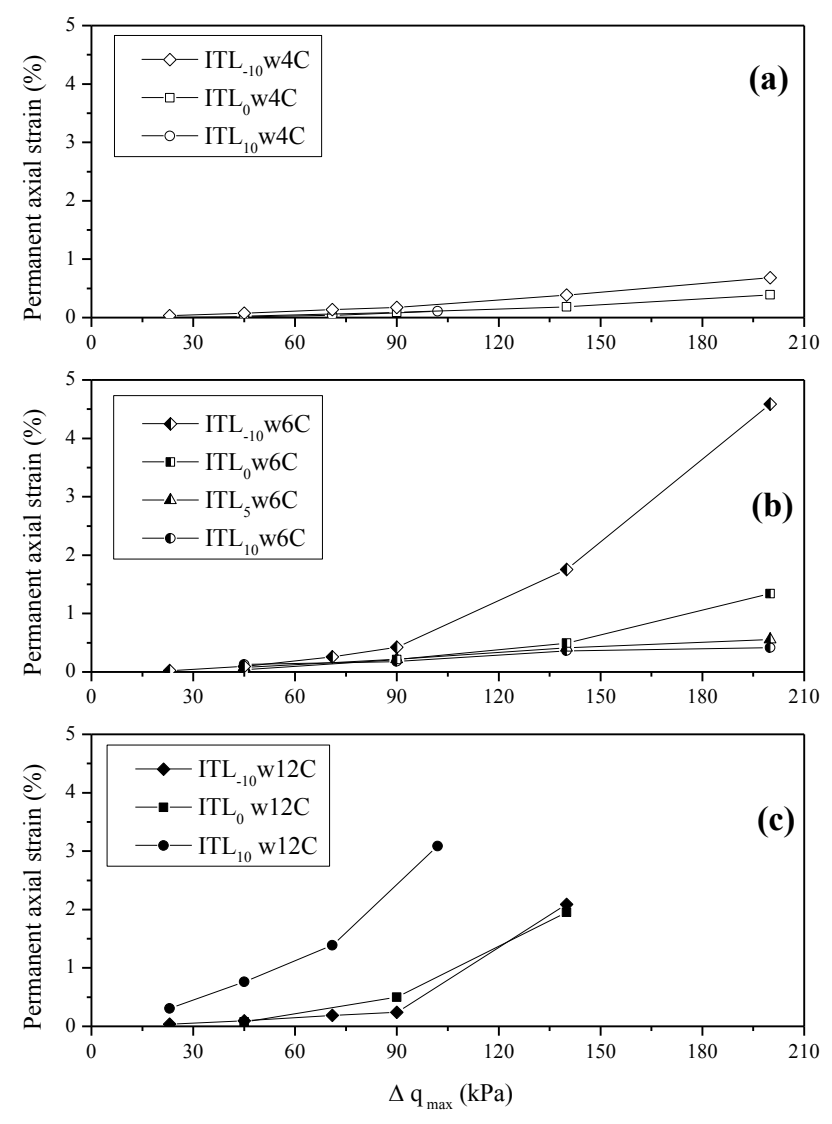

Figure 14. Effect of fines content on the end-stage permanent axial strain at various water contents.
On the whole, at a given water content in dry condition, adding more fines has a positive effect on the mechanical behavior of interlayer soil (the permanent axial strain is reduced), while in nearly saturated condition, adding more fines boosts the axial strain. This means that in the railway context, during the assessment and exploitation of the interlayer soil, the effect of water content and fines content must be taken into account simultaneously. The interlayer soil containing a larger quantity of fine particles have to be protected from water infiltration in order to avoid any increase of water content that would decrease its mechanical performance.

Gidel et al. [37] studied the permanent strain behaviour of two Unbound Granular Materials UGMs (0/20 limestone UGM and 0/10 UGM obtained from a micro-granite) following various stress paths with a $\Delta q / \Delta p$ ratio comprised between 0 and 3 . Based on the results obtained, they developed a constitutive model relating permanent axial strain to the maximum applied cyclic stress and the number of cycles. The general form of this model is as follows:

$$
\varepsilon_{1}^{p}=g\left(\Delta p_{\max }, \Delta q_{\max }\right) \cdot f(N)
$$

In this model, the effects of number of cycles and maximum applied stress are separated, making easier the determination of these functions. For the function $f(N)$, the model proposed by Hornych et al. [36] was adopted (Eq. 2). This model was verified and validated using the experimental results for UGMs.

$$
f(N)=\varepsilon_{1}^{p^{*}}=\varepsilon_{1}^{p}(N)-\varepsilon_{1}^{p}(100)=A\left(1-\left(\frac{N}{100}\right)^{-B}\right)
$$

(for $N>100$ cycles)

where $\varepsilon_{l} p^{*}$ is the permanent strain after the first 100 cycles, A and B are regression parameters. A depends on the stress level and the material; it represents the maximum permanent strain when the number of cycles tends to infinity. B controls the evolution of permanent strain with the increase of cycle number. According to Gidel et al. [37], this relationship is valid only for $N>$ 100 cycles because the first one hundred loading cycles correspond to the bedding down of the material.

For the function $g\left(\Delta p_{\max }, \Delta q_{\max }\right)$, Gidel et al. [37] showed that the permanent axial strain increases with the increase of mean stress $p$ and this axial strain increase is highly dependent on the stress path defined by $\Delta q_{\max } / \Delta p_{\max }$. The relationship between the permanent axial strain and the maximum applied stress in the case of $q>0$ is then given as follows:

$$
g\left(\Delta p_{\max }, \Delta q_{\max }\right)=\varepsilon_{1}^{p 0}\left(\frac{l_{\max }}{p_{a}}\right)^{n} \frac{1}{\left(m+\frac{s}{\Delta p_{\max }}-\frac{\Delta q_{\max }}{\Delta p_{\max }}\right)}
$$

where $\varepsilon_{l}^{p 0}, \mathrm{~m}, \mathrm{n}, \mathrm{s}$ are parameters; $p_{a}=100 \mathrm{kPa}$ and

$$
l_{\max }=\sqrt{\Delta p_{\text {max }}^{2}+\Delta q_{\text {max }}^{2}}
$$


The influence of water content on the mechanical behaviour of granular materials under cyclic loading has been observed experimentally in several studies [39-42]. The results obtained in this study on the interlayer soil are in agreement with these works. To extend the model of Gidel et al. [37] to the effect of water content or degree of saturation, a function relating the permanent axial strain to the water content and the applied deviator stress, $t(w$, $\Delta q_{\max }$ ), was defined, as follows [29, 9]:

$t\left(w, \Delta q_{\max }\right)=\varepsilon_{1}^{p 0} \cdot(w+a) \cdot\left(\frac{\Delta q_{\max }}{p_{a}}\right)^{\alpha}$

where $\varepsilon_{l}^{p 0}$, a and $\alpha$ are parameters and $p_{a}=100 \mathrm{kPa}$.

In order to account for the stress level, number of cycles and water content of soil, Eq. 4 is extended as follows:

$$
\varepsilon_{1}^{p}=t\left(w, \Delta q_{\max }\right) \cdot f(N)
$$

where $f(N)$ is calculated using Eq. 2 and $t\left(w, \Delta q_{\max }\right)$ is calculated using Eq. 4.

To validate the model, two tests on the natural interlayer soil of Sénissiat at two water contents, $w=4 \%$ (TC1) and $w=6 \%$ (TC2) are used for determining the model parameters. These parameters are then used to simulate a test on the saturated sample $(w=4 \%, \mathrm{TC} 3)$. The parameters determined are: $\varepsilon_{l}^{p 0}=9.14 \times 10-4, a=$ 3.36; $\alpha=2.54 ; A=0.76 ; B=0.17$.

Figure 15a shows that the proposed model fits well with the experimental results. For test $\mathrm{TC} 1$, in the last loading stage, the model value is close to the measured value at the end of the test; but for test TC2, larger difference between the simulation and the experimental results can be observed in the last loading stage. Figure $15 \mathrm{~b}$ presents a zoom of the results for the first three loading stages. It is observed that the simulation of test $\mathrm{TC} 1$ is better than that of test TC2. This is related to the final value of permanent axial strain at the end of each loading stage. Indeed, it was observed that stabilisation of permanent axial strain occurred for test TC1 but no stabilisation for TC2. Better simulation results can be expected if stabilised permanent axial strains are accounted for in the determination of parameters.

Figure 16 presents the comparison between the experimental results and the simulation for test TC3 (saturated state). It can be observed that the parameters determined from tests TC1 $(w=4 \%)$ and TC2 $(w=6 \%)$ enable a satisfactory simulation of test TC3 $(w=12 \%)$ for the first two loading stages. Significant differences between the simulation and the results are however observed for the third loading stage that corresponds to large deformations $\left(\varepsilon_{l}^{p}>150 \times 10^{-4}\right)$. This can be explained by the "shakedown theory" [43-44]. Actually, there are three categories of material response under repeated loading: plastic shakedown - category A (steady deformation behaviour), plastic creep - category B (failure at large number of cycles), and incremental collapse - category $\mathrm{C}$ (failure at low number of cycles). The critical stress levels can be defined according to the accumulated permanent axial strain. Following AFNOR
[45], the plastic creep limit is reached when $\varepsilon_{l}^{p}(5000)$ $\varepsilon_{l}^{p}(3000)>4 \times 10^{-4}$ for UGMs, where $\varepsilon_{l}^{p}$ (5000), $\varepsilon_{l}^{p}$ (3000) are the accumulated permanent axial strains at 5000 cycles and 3000 cycles, respectively. For the interlayer soil, this value is $1 \times 10^{-4}$ for TC1, $4 \times 10^{-4}$ for $\mathrm{TC} 2$ in the last loading stage, and $5.6 \times 10^{-4}$ for TC3, in the third loading stage. This shows that tests TC1 and TC2 are of categories A and B respectively at a deviator stress $\Delta q_{\max }=200 \mathrm{kPa}$, while test TC3 at $\Delta q_{\max }=140 \mathrm{kPa}$ entre category $\mathrm{C}$. This means that the proposed model can only fit well with the permanent deformation of categories $\mathrm{A}$ and $\mathrm{B}$.

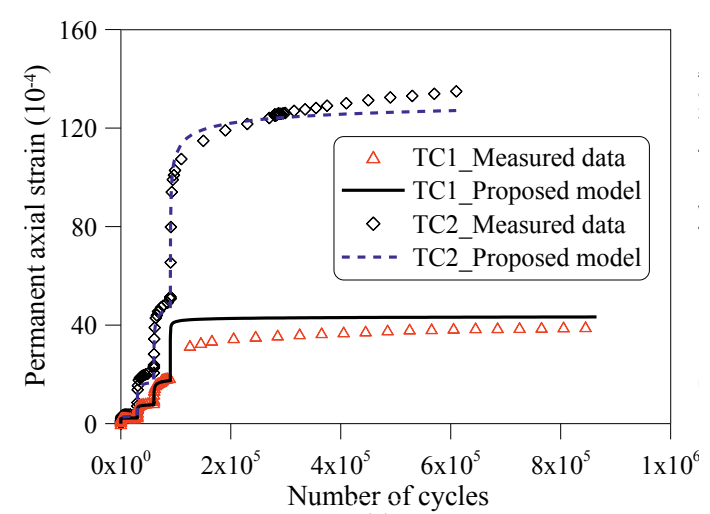

(a)

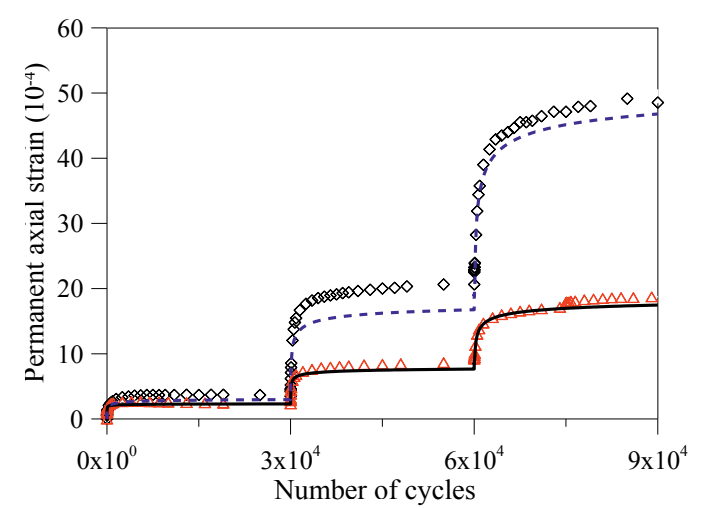

(b)

Figure 15. Determination of parameters by fitting the experimental results from tests TC1 $(w=4 \%)$ and TC2 $(w=$ $6 \%$ ).

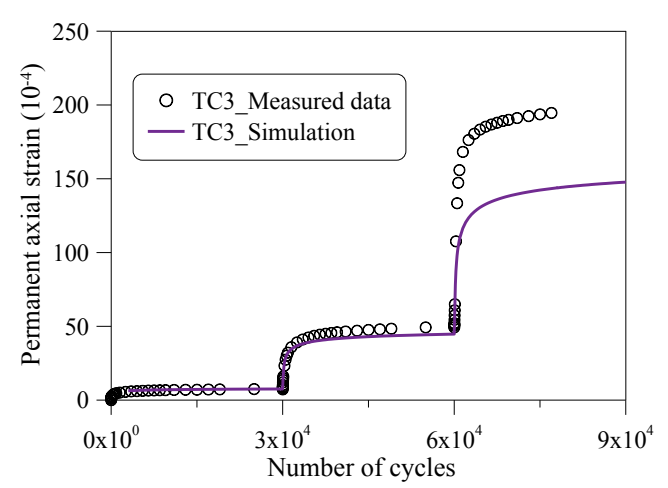

Figure 16. Verification of the proposed model - Simulation of test TC3 (saturated state). 


\subsection{Physical modelling of interlayer creation of mud-pumping phenomena}

Mud pumping which is characterized by the fast upward migration of subgrade fine particles through the ballast voids has been known to be the worst degradation phenomenon for the railway substructure. This phenomenon was reported by several authors [39, 46-52]. Basically, the phenomena of interlayer creation and mud pumping are both related to the migration of fine particles and the interaction between ballast and subgrade. Thus, a good knowledge on the mechanism related to the migration of fine particles is crucial for better understanding the interlayer creation and the mudpumping, and also for further proposing efficient and economic methods for railway track maintenance.

A physical model was developed for this purpose [5354]. Figure 17 show it with a 3D view (Figure 17a), a side view (Figure 17b) and a view of cross section A-A (Figure 17c). The cylindrical cell has an internal diameter of $550 \mathrm{~mm}$, a wall thickness of $20 \mathrm{~mm}$ and a height of $600 \mathrm{~mm}$. The wall was made of Poly (methyl methacrylate) - PMMA which is a transparent thermoplastic allowing the observation of sample from outside. A digital camera connected to a computer, allowing the visual monitoring of the ballast/sub-soil interface. Three time-domain refectory probes (TDR1 to TDR3) embedded in the sub-soil $(h=120,160,200 \mathrm{~mm})$ allowed the volumetric water content to be monitored. Three tensiometers (T1 to T3) [55-58] installed in couple with TDRs at different heights $(h=120,160,200 \mathrm{~mm})$ were used for suction monitoring. One pressure sensor was installed at the bottom of the apparatus $(h=0 \mathrm{~mm})$ for measuring the positive pore water pressure under saturated conditions. A hydraulic actuator with the integrated displacement and force sensors was used for monotonic or cyclic loadings.

A silt was used as subgrade soil. It was compacted in five layers of $40 \mathrm{~mm}$ thick each and one layer of $20 \mathrm{~mm}$ thick, making a total of $220 \mathrm{~mm}$ thickness for the whole subgrade layer. For the dry unit mass, three values were considered: $1.4,1.5$ and $1.6 \mathrm{Mg} / \mathrm{m}^{3}$. The TDR probes were placed between the compaction layers. A $160 \mathrm{~mm}$ ballast layer was placed on the sub-soil and the surface of ballast layer was arranged in order to be horizontal for ensuring a good ballast/piston contact. The whole apparatus was put under the hydraulic actuator. Finally, the tensiometers were installed.

All the tests started with the sub-soil in unsaturated state $(w=16 \%)$ and with a pre-loading stage: monotonic loading from 0 to $100 \mathrm{kPa}$ at a rate of $2 \mathrm{kN} / \mathrm{min}$; lowfrequency cyclic loading from 30 to $100 \mathrm{kPa} ; 0.1 \mathrm{~Hz}$ cyclic loading for 20 cycles; $1 \mathrm{~Hz}$ cyclic loading for 50 cycles and $2 \mathrm{~Hz}$ cyclic loading for 100 cycles. Afterwards, a $5 \mathrm{~Hz}$ cyclic loading for 500000 cycles was applied. The value of $5 \mathrm{~Hz}$ frequency represents the train circulation at $100 \mathrm{~km} / \mathrm{h}$ and the applied stress was chosen according to the stress distribution in the conventional railway tracks in France.

In order to study the effect of water content or degree of saturation, once the 500000 cycles ended, the sub-soil was saturated from the bottom under a hydraulic head of $12 \mathrm{kPa}$. After saturation, the water level was maintained at $20 \mathrm{~mm}$ above the ballast/sub-soil interface in order to ensure the saturated state of the sub-soil. Before the loading under saturated condition, a pressure sensor was installed at $h=0 \mathrm{~mm}$. Monotonic loading at the same rate as in the unsaturated case was then applied followed by the $5 \mathrm{~Hz}$ cyclic loading. The test ended when fine particles were observed on the surface of the ballast layer or when the number of cycles reached 500000 .

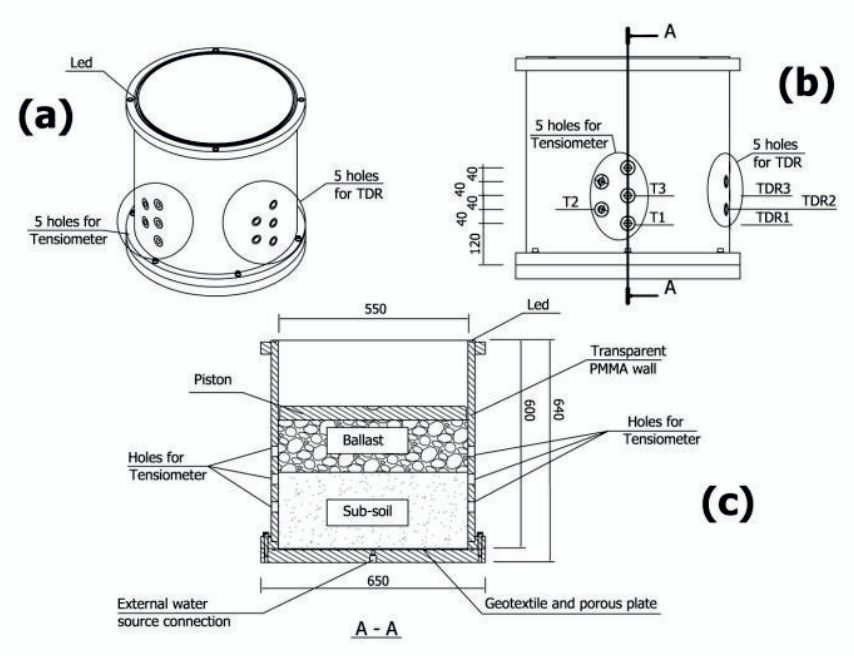

Figure 17. Schematic view of the apparatus developed.

The photographs taken by the digital camera before and after loading for $1.4 \mathrm{Mg} / \mathrm{m}^{3}$ allowed the visualization of the movement of ballast particles and the evolution of the sub-soil surface (Figure 18). A limited ballast movement can be seen and the ballast/sub-soil interface did not change significantly. The same phenomenon was observed for the two other densities, 1.5 and $1.6 \mathrm{Mg} / \mathrm{m}^{3}$.

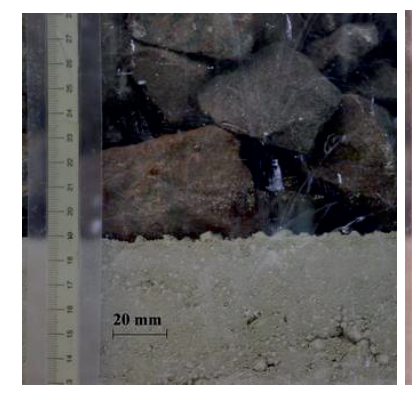

(a)

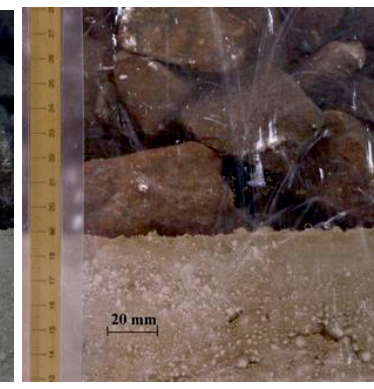

(b)
Figure 18: Photographs of the ballast/sub-soil interface: a) before monotonic loading and b) after 500000 cycles $5 \mathrm{~Hz}$ loading $\left(w=16 \%\right.$ and $\left.\rho_{\text {d-initial }}=1.4 \mathrm{Mg} / \mathrm{m}^{3}\right)$. 


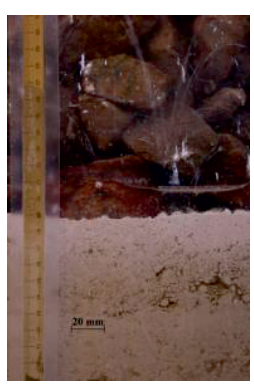

(a)

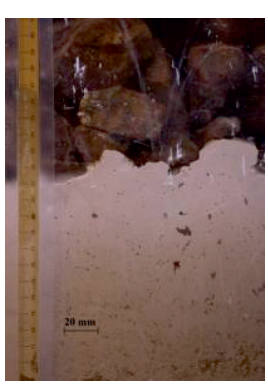

(b)

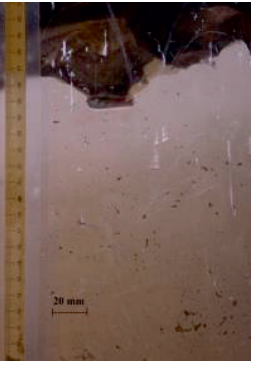

(c)
Figure 19: Photographs showing the evolution of the ballast/sub-soil interface $\left(\rho_{d \text {-initial }}=1.4 \mathrm{Mg} / \mathrm{m}^{3}\right)$.

The photographs taken at the ballast/sub-soil interface at three moments (after the saturation, after the monotonic loading and after the cyclic loading) are presented in Figure 19. It can be observed that the fine particles were pumped up significantly especially during the cyclic loading. In the test at $1.5 \mathrm{Mg} / \mathrm{m}^{3}$ dry density, also significant migration of fine particles was identified. However, this migration was found limited in the test at $1.6 \mathrm{Mg} / \mathrm{m}^{3}$.

During the loadings under saturated condition, five reference vertical sections were chosen and the interface evolutions at these sections were analyzed and presented in Figure 20. In general, the interface evolutions followed the same trend and the pumping levels of fine particles are uniform across the section. This is confirmed by the visual observation after the tests. Two key moments (start of monotonic and cyclic loadings) can be clearly identified by the distinguished changes of pumping level.

In order to verify the nature of the migration of fine particles, a comparison was made between the volume of ballast particles penetrated into the sub-soil V1 and the volume of ballast layer voids filled by the pumped up fine particles V2:

$$
\begin{aligned}
& V_{1}=\frac{h_{1} \times A}{1+e} \\
& V_{2}=\frac{h_{2} \times A}{1+e} e
\end{aligned}
$$

where $\mathrm{h} 1$ is the settlement of ballast layer, A is the sample cross section and $\mathrm{e}$ is the void ratio of ballast layer, $h_{2}$ is the pumping up level of fine particles in the ballast layer.

Assuming that the volume of fine particles migrated due to the ballast particles penetration and the fine particles filling the voids of the ballast layer are equal, i.e., $V_{I}=V_{2}$, the following expression can be obtained:

$$
h_{2}=\frac{h_{1}}{e}
$$

Indraratna et al. [59] reported that the void ratio of ballast e can vary from 0.74 (compacted) to 0.95 (uncompacted). A value of 0.75 was proposed by Tutumluer et al. [60] and Huang et al. [36]. In this study, as the sample underwent 500000 cycles of $5 \mathrm{~Hz}$ loading, the ballast layer can be considered as compacted. From Eq. 7, the theoretical pumping level of fine particles is calculated using $e=0.74$ and plotted also in Figure 20. It can be seen clearly that the theoretical pumping level for
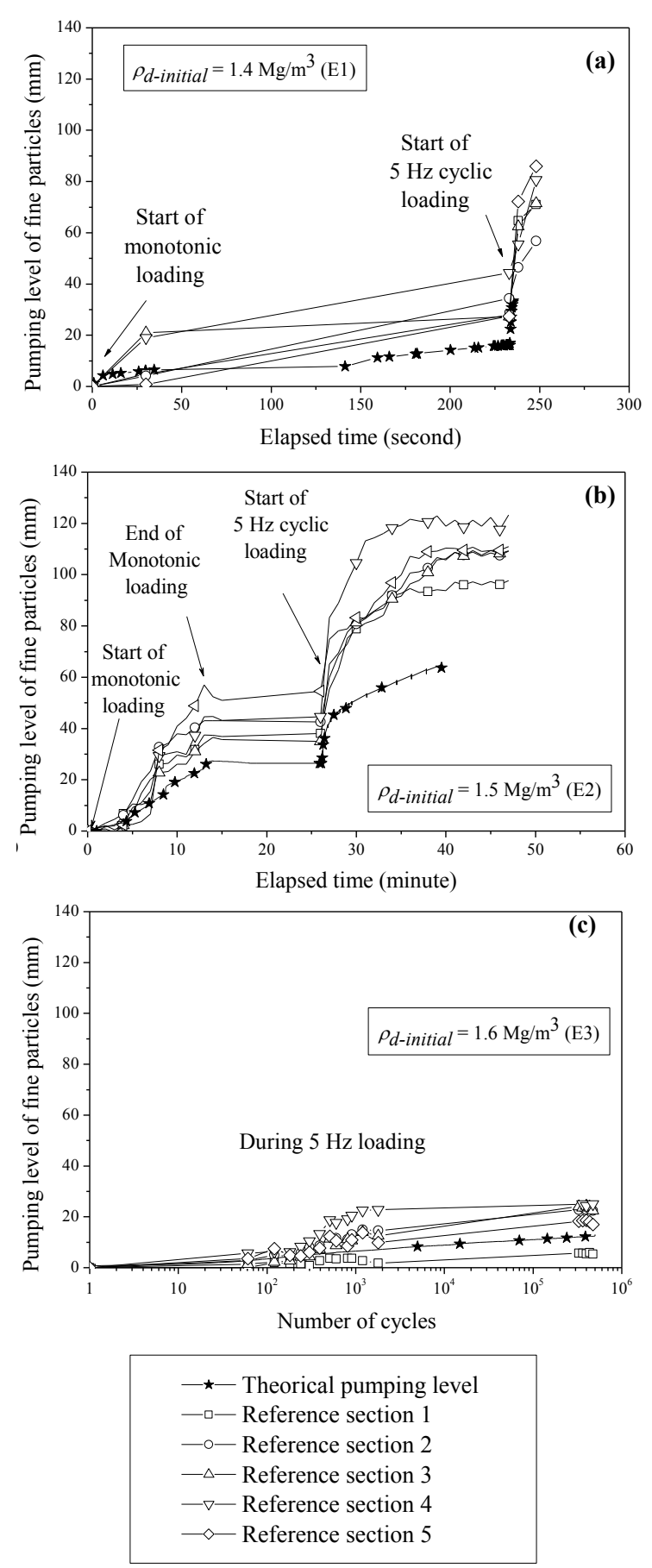

Figure 20. Pumping level of fines particles.

tests at 1.4 and $1.5 \mathrm{Mg} / \mathrm{m}^{3}$ are much smaller than the real pumping level deduced from the photographs. This suggests that fine particles moved up not only because of the ballast penetration, but also the dissipation of excess pore water pressure. This corresponds to the phenomenon of mud pumping. By contrast, in the case of test at $1.6 \mathrm{Mg} / \mathrm{m}^{3}$, the theoretical curve stays in the middle of those of reference sections. This suggests that the migration of fine particles was solely due to the ballast penetration. This corresponds to the phenomenon of interlayer creation. Thus, the stiffness of subgrade plays an essential role in the creation of interlayer or in the phenomenon of mud pumping. This is consistent with a case study conducted by Duong et al. [61]. 
In reality, most sub-soils are not always saturated. This explains why the interlayer creation is more common than the mud pumping.

\section{Field investigation}

To investigate the behaviour of railway tracks, it is of paramount importance to conduct field monitoring with real train loadings, real composition of tracks as well as real climatic conditions. The field monitoring includes several parts: i) acceleration due to wheel-rail interactions, ii) surface acceleration/velocity and displacement under train loadings, iii) acceleration/velocity and displacement in the track-bed under train loadings, iv) interaction between the atmosphere and track-bed. In this section, an example of field monitoring focusing on the atmosphere/track-bed interaction is presented [62].

The experimental site is at Moulin Blanc, located in the region of Nord - Pas de Calais, France, in the middle of the 'Douai - Valenciennes' line that was constructed in the late XIXth century. This site is in a cutting zone, and was instrumented at PK $230+400$ of the line number 262000 of the French railway network. Different trains are involved: High velocity (TGV), Intercity (TER) and Freight. The train velocity at the site is limited to $110 \mathrm{~km} / \mathrm{h}$. Different soils were identified at this site, in particular the interlayer soil of blackish colour with a thickness varying from $10 \mathrm{~cm}$ to $57 \mathrm{~cm}$, and the subgrade soil consisting of either sandy or clayey silt. The thickness of the ballast layer is about $50 \mathrm{~cm}$, with about $30 \mathrm{~cm}$ fresh ballast and $20 \mathrm{~cm}$ fouled ballast.

The field instrumentation was done at PK $230+400$ of the line. Based on the depth of interlayer, it was decided to install the suction/temperature probes at $-0.20,-0.30$ and $-0.50 \mathrm{~m}$ depths under the ballast layer in two zones $\mathrm{A}$ and $\mathrm{B}$, at $20 \mathrm{~m}$ distance from each other (see Figure $21 \mathrm{a}$ ). Two other suction/temperature probes were installed in a zone out of tracks (zone C) and at -0.30 and $-0.50 \mathrm{~m}$ depths. A temperature sensor was installed at the platform surface in zone C. A total of 8 suction probes and 9 temperature sensors were installed. A weather station was installed on the top of the excavation slope to monitor solar radiation, air temperature, air humidity and rainfall (see Figure 21b). Two piezometers of $10 \mathrm{~m}$ depth each were installed near zone A and zone B respectively for the water table monitoring (see Figure 21b).

Four piezo-electric accelerometers ICP/PCB-601A12 were also used, with a measurement range of $\pm 10 \mathrm{~g}$, a frequency ranging from $0.47 \mathrm{~Hz}$ to $4000 \mathrm{~Hz}$ and a resonant frequency of $16000 \mathrm{~Hz}$. Two were implemented in zone $\mathrm{A}$ at -0.10 and $-0.40 \mathrm{~m}$ depths respectively, and two others in zone $B$ at -0.10 and $-0.40 \mathrm{~m}$ depths respectively (see Figure 21). Moreover, strain gauges were glued on the rail for the measurement of rail strain under the passages of trains.

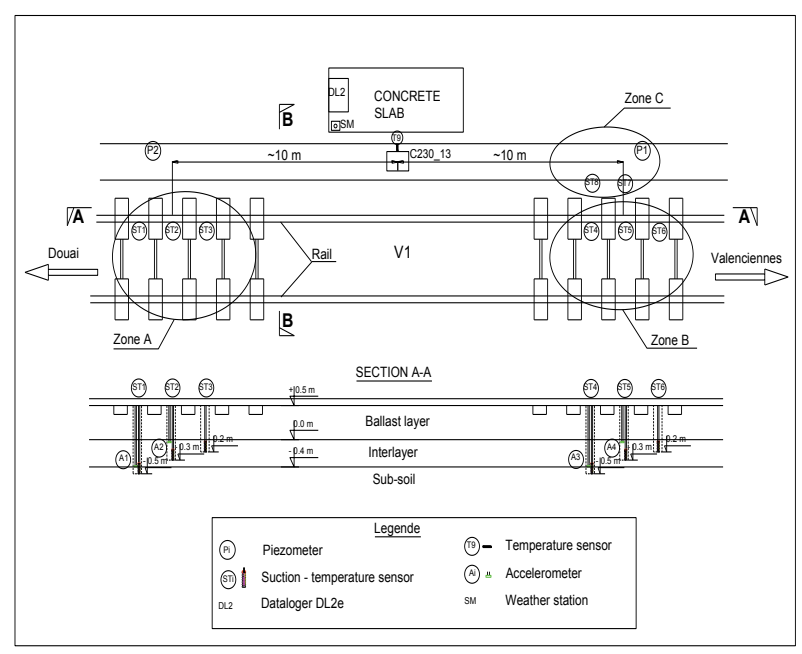

(a)

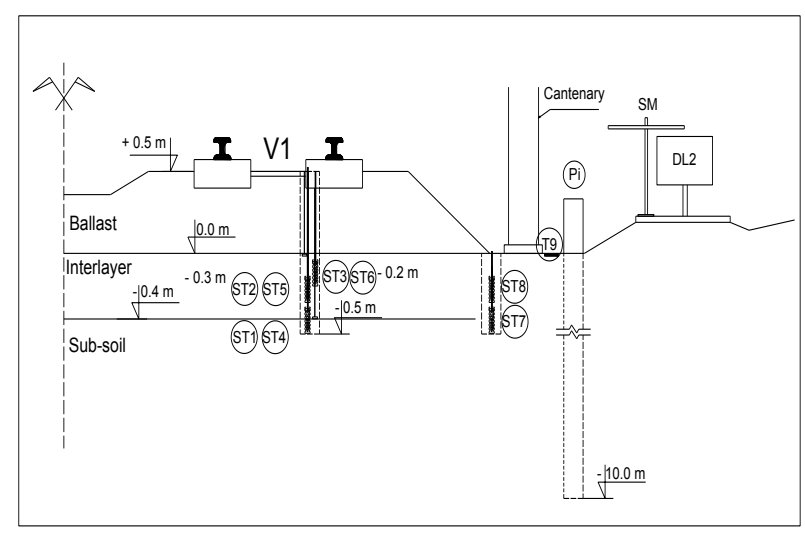

(b)

Figure 21. Site instrumentation. (a) Longitudinal section; (b) Transversal section.

Figure 22 depicts the evolutions of the air parameters measured by the weather station, including air temperature (Figure 22a), solar radiation (Figure 22b), wind speed (Figure 22c), relative humidity ( Figure 22d) and precipitation (Figure 22e). Note that due to a technical problem, the monitoring of relative humidity was interrupted in the beginning and in the middle of the recording period. It appears that the solar radiation directly conditions the air temperature: in winter the solar radiation is low giving rise to low air temperatures, whereas in summer the solar radiation is higher generating higher temperatures. For the wind speed, it appears that there are few differences from one season to another, except the exceptional wind recoded in early November 2009 at a speed close to $12 \mathrm{~m} / \mathrm{s}$. The variations of relative humidity are more pronounced in the period from March to July 2010 than in the period from September to December 2009. This is consistent with the precipitation. Indeed, there were more strong rainfalls in the second period that in the first (see Figure 22e). Note that all data presented in Figure 22 correspond to a recording frequency of $30 \mathrm{~min}$.

The air data presented in Figure 22 can be used to determine the potential evaporation rate using the model of Penman-Monteith [63]: 


$$
E T_{0}=\frac{0.408 \Delta\left(R_{n}-G\right)+\gamma \frac{900}{T+273} u_{2}\left(e_{s}-e_{a}\right)}{\Delta+\gamma\left(1+0.34 u_{2}\right)}
$$

where

$E T_{0}$ is the potential evaporation $\left(\mathrm{mm} \cdot \mathrm{day}^{-1}\right)$;

$R_{n}$ is the net solar radiation (MJ. $\mathrm{m}^{-2} \cdot$ day $^{-1}$ );

$G$ is the soil heat flux $\left(\mathrm{MJ}^{-2} \mathrm{~m}^{-2}\right.$. $\left.\mathrm{day}^{-1}\right)$;

$T$ is the daily average temperature at $2 \mathrm{~m}$ above the ground surface $\left({ }^{\circ} \mathrm{C}\right)$;

$u_{2}$ is the wind speed at $2 \mathrm{~m}$ above the ground surface $\left(\mathrm{m} . \mathrm{s}^{-1}\right)$;

$e_{s}$ is the saturated vapour pressure $(\mathrm{kPa})$;

$e_{a}$ is the actual vapour pressure that can be deduced from the air relative humidity using Kelvin's law $(\mathrm{kPa})$;

$\Delta$ is the slope of the curve of saturated vapour pressure versus temperature $\left(\mathrm{kPa}^{\circ}{ }^{\circ} \mathrm{C}^{-1}\right)$;

$\gamma$ is the psychometric constant $\left(\mathrm{kPa} \cdot{ }^{\circ} \mathrm{C}^{-1}\right)$.
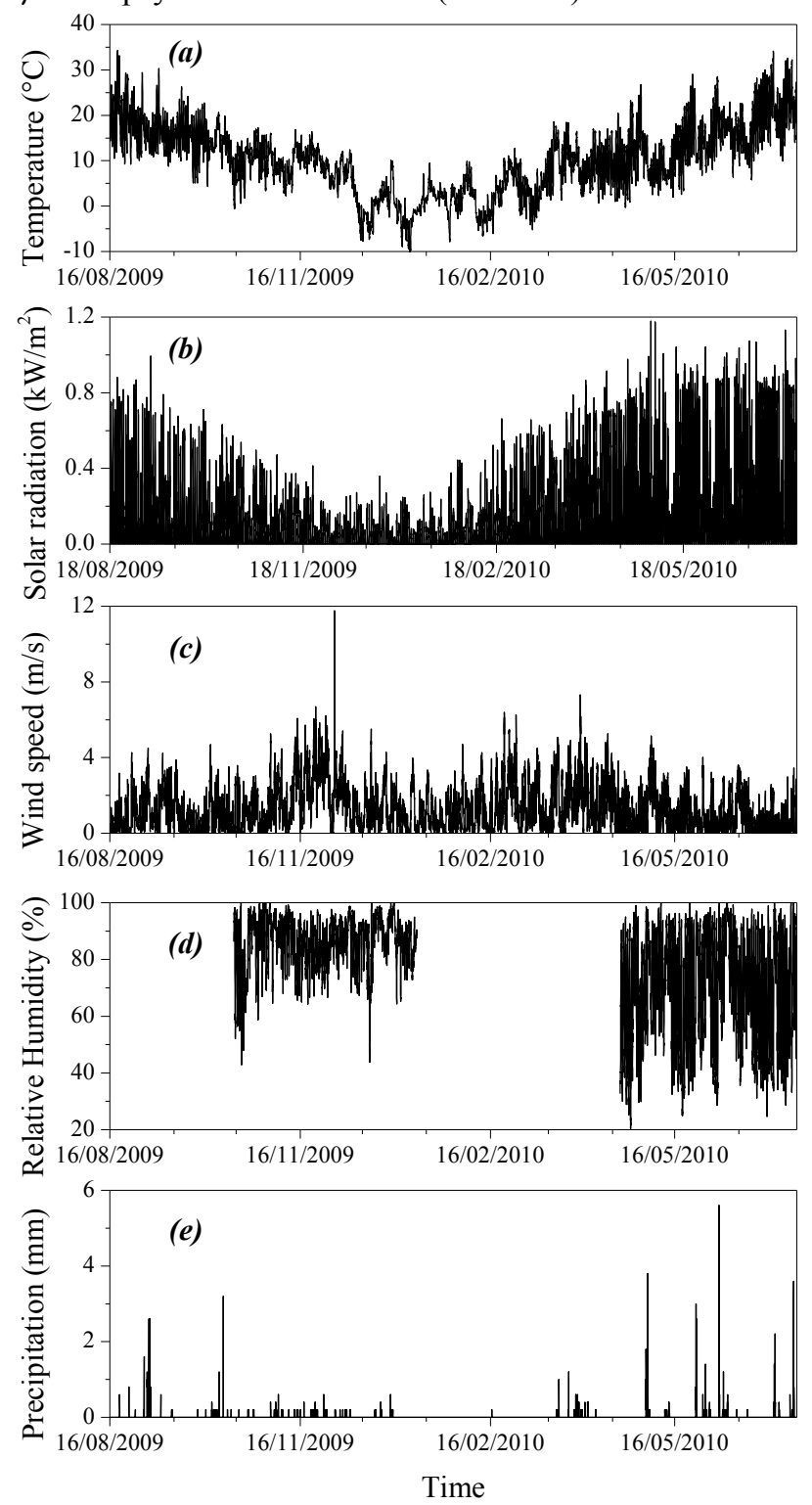

Figure 22. Air data. (a) Temperature; (b) Solar radiation; (c) Wind speed; (d) Relative humidity; (e) Precipitation.
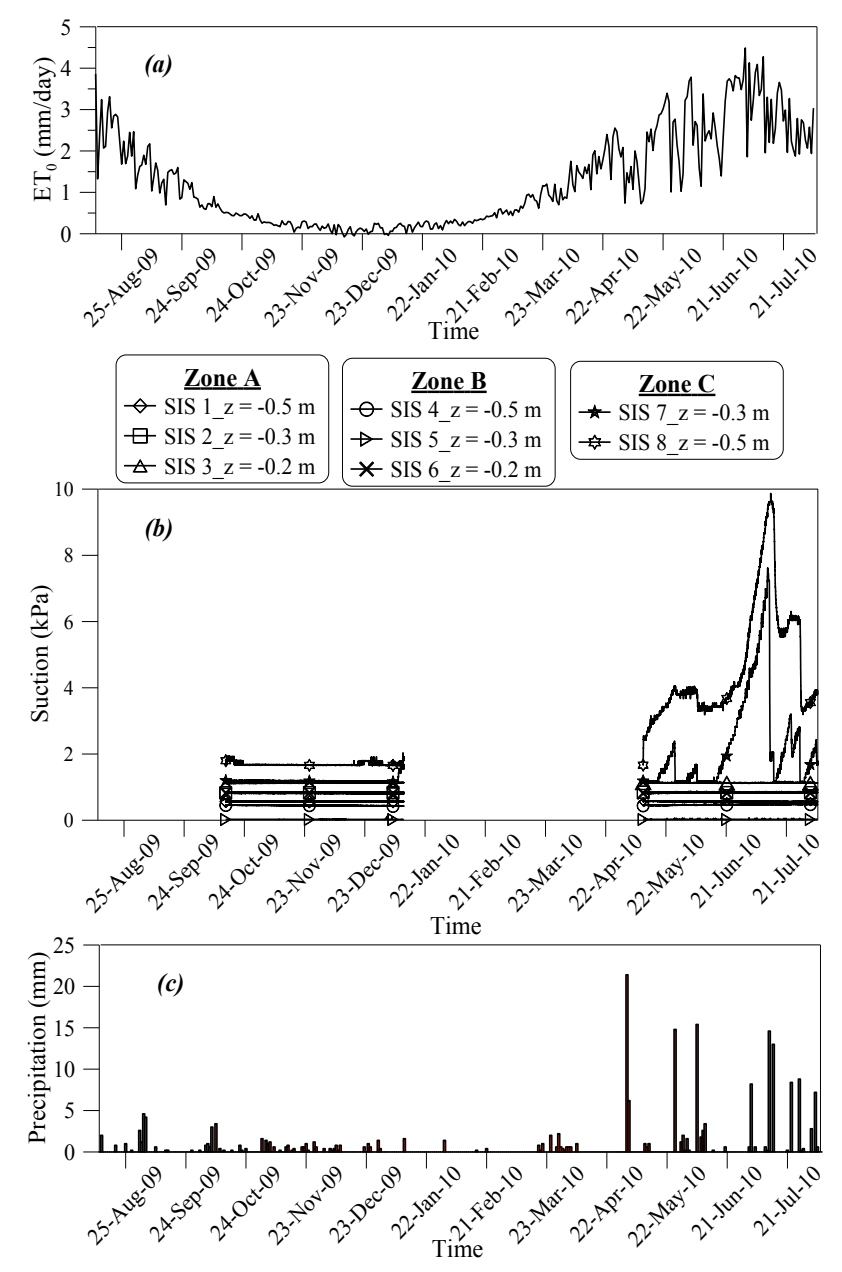

Figure 23. Potential evaporation (a), suction (b) and daily rainfall (c).

As mentioned before, the measurements of air relative humidity were not complete in the monitoring period. Thereby, the data recorded in a Méteo France weather station in Cambrai (close to the Moulin Blanc site) were used in the calculation. Figure 23a shows the variations of $\mathrm{ET}_{0}$ over the monitoring period. It appears clearly that the value of $\mathrm{ET}_{0}$ is large in summer and small even equal to zero in winter, in agreement with the variations of solar radiation and air temperature shown in Figure 22.

Figure $23 \mathrm{~b}$ shows the variations of suction in the three zones and at different depths. Again, because of the technical recording problem mentioned previously, the data are not complete and only the period from September to December 2009 and the period from April to July 2010 are covered. From the limited available data, it appears that in the relatively cold season (from September to December 2009), the suction values remained stable and small in all the three zones. By contrast, in the hot season (from April to July 2010), the values in zone $\mathrm{A}$ and zone $\mathrm{B}$ still remained stable but showed large variations in zone $\mathrm{C}$. The difference between zone $\mathrm{A} /$ zone $\mathrm{B}$ and zone $\mathrm{C}$ is to be attributed to the effect of ballast layer.

Figure 23c shows the daily precipitation in the monitoring period. The difference between this figure and Figure $22 \mathrm{e}$ is that the former corresponds to a frequency 
of every day (precipitation amount for each day) whilst the latter corresponds to a frequency of every $30 \mathrm{~min}$ (precipitation amount for every $30 \mathrm{~min}$ ). It can be observed that adopting a different frequency significantly changes the precipitation distribution feature: more details can be found with a high frequency (30 min) while the precipitation values are more averaged in the case of low frequency (one day). It appears in Figure 23c that the strong rainfall events occurred in the period from April to July 2010. This suggests that the large variations of suction identified in zone $\mathrm{C}$ in this period (see Figure $22 \mathrm{~b}$ ) are not related to the rainfalls, but to the high water evaporation rate. In other words, at the site of Moulin Blanc in the monitoring period the evaporation rate was larger than the water infiltration rate in the zone out of tracks - the soil was being dried over time. This explains why no water table was detected by the two piezometers installed till $10 \mathrm{~m}$ depth. Further examination shows that under the ballast layer (zones A and B) suction did not change, indicating the effective protection of the ballast layer against water evaporation on one hand and water infiltration on the other hand.

\section{Conclusion}

The hydro-mechanical behaviour of unsaturated railway track-bed materials were investigated through laboratory testing, physical modelling as well as field monitoring. The results obtained allow the following conclusions to be drawn.

The Geo-endoscopic tests allow the identification of different materials constituting the platform, their natures and thicknesses. A good correlation of thicknesses is obtained between the geo-endoscopic tests and the PANDA penetrometer tests. This site prospection is essential to well define the soil profile, in particular the interlayer position.

Hysteresis exists for both the soil water retention curve and the hydraulic conductivity changes with suction. The wetting process was found to be much faster than the drying process, and the hydraulic conductivity during wetting is always higher than that during drying.

The water retention curves of $\mathrm{ITL}_{10}$ and fines are different, illustrating an obvious effect of soil texture. On the contrary, in terms of unsaturated hydraulic conductivity, a good agreement was identified between the results of two soils, regardless of the drying or wetting paths. This suggests that water transfer in the unsaturated interlayer soil takes place mainly through the network of pores between fine particles, coarse elements like ballast behaving as inert materials. On the contrary, in saturated state, a higher value was obtained for ITL $\mathrm{IL}_{10}$, suggesting that in this case the hydraulic conductivity is mainly governed by the water flow through macro-pores. Thereby, the water flow mechanism in saturated state is different from that in unsaturated state. From a practical point of view, this finding shows that to determine the unsaturated hydraulic conductivity of interlayer soils, a device as small as the small-scale infiltration cell can be employed by testing the fine particles only, provided that equivalent dry density is taken into account. However, this is not valid for the determination of saturated hydraulic conductivity.

The effects of water content and of fines content on the resilient modulus are linked. Indeed, under unsaturated conditions, due to the suction effect, the soil having high fines content showed higher resilient modulus. On the contrary, when the soil approached the saturated conditions, the fine particles provided a negative effect.

In terms of permanent axial strain, it was also observed that in dry condition $(w=4 \%$ and $6 \%)$, adding fines decreases the permanent axial strain due to the suction effect. On the contrary, in nearly saturated condition $(w=12 \%)$, the higher the fines content the higher the axial permanent strain. This is because that the interlayer soil is weakened mechanically due to the sensitivity of fine particles to water content changes in nearly saturated condition. From a practical point of view, the increase of fines content on the mechanical behavior of interlayer is acceptable in case of lower water content (dry state). But in case of high water content (nearly saturated state), the interlayer with high fines content needs to be protected from water infiltration. Otherwise, significant decrease in mechanical performance can be expected.

In order to predict the permanent axial strain, a constitutive model accounting for the effects of stress level, number of cycles and water content of soil was developed based on the results of cyclic triaxial tests with multi-stage loading procedure and the model proposed by Gidel et al. [37]. The parameters were first determined by fitting the tests with $4 \%$ and $6 \%$ water contents. The parameters determined were then used to simulate the test corresponding to the saturated state $(w=12 \%)$. The simulation was in good agreement with the experimental results, indicating the performance of the proposed model for the prediction of permanent deformation within categories A and B. Further study is however necessary to better describe the deformation behaviour for category C.

The presence of water was found to be the most crucial factor for the migration of fine particles. In the unsaturated state, both the ballast and sub-soil settlements occurred, but without the migration of fine particles. Under the near saturated state, the ballast/sub-surface interface moved up, and the pumping level depends on the sub-soil dry unit mass. In the case of $\rho_{\text {d-initial }}=$ $1.4 \mathrm{Mg} / \mathrm{m}^{3}$ and $1.5 \mathrm{Mg} / \mathrm{m}^{3}$, excess pore water pressure dissipation took place, bringing fine particles upward. This corresponds to the mud pumping phenomenon. In the case of $\rho_{\text {d-initial }}=1.6 \mathrm{Mg} / \mathrm{m}^{3}$, there was just the interpenetration of ballast and sub-soil, resulting in a mixture layer namely interlayer.

In the field conditions, the suction under the ballast layer remained low and unchanged over long time. However, significant changes can take place in the zone where the soil ground is directly exposed to the atmosphere without being covered by ballast. These changes are mainly due to water evaporation. Comparison between the potential evaporation rate and the precipitation at the site of Moulin Blanc showed that 
the site was in deficiency in water supply. This explained the absence of water table till the depth of the installed piezometers $(10 \mathrm{~m})$.

\section{Acknowledgements}

The author would like to thank all his co-workers from Ecole des Ponts ParisTech - ENPC (Trong Vinh Duong, Viet Nam Trinh, Francesco Lamas-Lopez, Anh Minh Tang, Jean-Claude Dupla, Jean Canou) and from the French Railway Company - SNCF (Nicolas Calon, Alain Robinet, Sofia Costa D'Aguiar, Lucie Lambert, Olivier Schoen).

\section{References}

1. Y.J. Cui, A.M. Tang, D. Marcial, J.M. Terpereau, G. Marchadier, X. Boulay. Geotech. Test. J. 30(3), 227233 (2007)

2. C. Yang, Y.J. Cui, J.M. Pereira, M.S. Huang. Comput. Geotech. 35, 853-859 (2008)

3. J.P. Karam, Y.J. Cui, A.M. Tang, J.M. Terpereau, G. Marchadier. Soils Found. 49(3), 421-429 (2009)

4. J.A. Munoz-Castelblanco, J.M. Pereira, P. Delage, Y.J. Cui. Géotechnique 62(2), 95-106 (2011)

5. J.A. Munoz-Castelblanco, J.M. Pereira, P. Delage, Y.J. Cui. Geotech. Test. J. 35(1), 11-17 (2012a)

6. J.A. Munoz-Castelblanco, P. Delage, J.M. Pereira, Y.J. Cui. Géotechnique 62(7), 595-604 (2012b)

7. A.M. Tang, Y.J. Cui, V.N. Trinh, Y. Szerman, G. Marchadier. Eng. Geol. 106(1-2), 68-77 (2009)

8. V.N. Trinh, A.M. Tang, Y.J. Cui, J. Canou, J.C. Dupla, N. Calon, L. Lambert, A. Robinet, O. Schoen. R. F. G. 134-135, 65-74 (2011)

9. Y.J. Cui, T.V. Duong, A.M. Tang, J.C. Dupla, N. Calon, A. Robinet. J. Zhejiang Univ. Sci. A 14(4), 244-255 (2013).

10. F. Lamas-Lopez, Y.J. Cui, N. Calon, S. Costa D’Aguiar. Soils Found. 56(2), 240-250 (2016)

11. G. Degrande, L. Schillemans. J. Sound Vibration 247(1), 131-144 (2001).

12. L.J. Su, C. Rujikiatkamjorn, B. Indraratna. (2010). Geotech. Test. J. 33(5) (2010)

13. T.R. Sussmann, E.T. Selig, J.P. Hyslip. NDT \& E INT, 157-167 (2003)

14. J. Hunter, B. Benjumea, J. Harris, R. Miller, S. Pullan, R. Burns, R. Good. Soil Dyn. Earthq. Eng. 22(9-12), 931-941 (2002)

15. Z. Tompai. Period. Polytech-Civ. 52, 97-102 (2008)

16. P.K. Woodward, J. Kennedy, O. Laghrouche, D.P. Connolly, G. Medero. Transportation Geotechnics 1(4), 214-224 (2014)

17. V. Alves Fernandes, F. Lopez-Caballero, S. Costa d'Aguiar. Comput. Geotech. 55, 267-276 (2014)

18. T.V. Duong, Y.J. Cui, A.M. Tang, J.C. Dupla, N. Calon. Can. Geotech. J. 51(7), 735-746 (2014a)
19. T.V. Duong, V.N. Trinh, Y.J. Cui, A.M. Tang, N. Calon 2013. Geotech. Test. J. 36(1), 54-63 (2013a)

20. T.T. Le, Y.J. Cui, J.J. Muñoz, P. Delage, A.M. Tang, X.L. Li. Front. Archit. Civ. Eng. China 5(2), 160 170 (2011)

21. D.E. Daniel. Soil Sci. Am. J. 46(6), 1125-1129 (1982)

22. P. Delage, Y.J. Cui. 2001. Article C302. Ed. Techniques Ingénieur (2001)

23. L.B. Bruckler, P. Angulo-Jaramillo, R. Ruy. Soil Sci. Am. J. 66, 384-395 (2002)

24. Y.J. Cui, A.M. Tang, C. Loiseau, P. Delage. Phy. Chem. Earth PT A/B/C, 33, S462-S471 (2008a)

25. W.M. Ye, Y.J. Cui, L.X. Qian, B. Chen. Eng. Geol. 108(3), 169- 176 (2009)

26. A. Wayllace, N. Lu. Geotech. Test. J.35(1), 1-15 (2011)

27. N. Toker, J. Germaine, K. Sjoblomt, P. Culligan. Géotechnique 54(3), 179-186 (2004)

28. J. Côté, M. Roy. 1998. Rapport de l'études et recherches en transports du Québec, 177p (1998)

29. V.N. Trinh, A.M. Tang, Y.J. Cui, J. Canou, J.C Dupla, N. Calon, L. Lambert, A. Robinet, O. Schoen. Soils Found. 52(3), 511-523 (2012)

30. T.V. Duong, A.M. Tang, Y.J. Cui, V.N. Trinh, J.C. Dupla, N. Calon, J. Canou, A. Robinet. Soils Found. 53(6), 868-878 (2013b)

31. T.V. Duong, Y.J. Cui, A.M. Tang, J.C. Dupla, J. Canou, N. Calon, A. Robinet. Acta Geotech. 51-59 (2016)

32. F. Lekarp, U. Isacsson, A. Dawson. J. Transp. Eng. 126(1), 66-75 (2000)

33. L. Uthus, I. Hoff, I. Horvli. Proceeding of the 7th International Conference on the Bearing Capacity of Roads, Railways and Airfields. Trondheim, Norway, 1-13 (2005)

34. E. Fortunato, A. Pinelo, M. Matos Fernandes. Soils Found. 50(1), 55-62 (2010)

35. S. Seif El Dine, J.C. Dupla, R. Frank, J. Canou, Y. Kazan. Can. Geotech. J. 47(4), 425-438 (2010)

36. H. Huang, E. Tutumluer, W. Dombrow. T.R.B. 2117, 93-101 (2009)

37. G. Gidel, P. Hornych, J.J. Chauvin, D. Breysse, A. Denis. Bulletin de Liaison des Laboratoires des Ponts et Chaussées 233, 5-21 (2001)

38. P. Hornych, J.F. Corté, J.L. Paute. Bulletin de Liaison des Laboratoires des Ponts et Chaussées 184, 77-84 (1993).

39. E.T. Selig, J.M. Waters. Thomas Telford (1994)

40. G. Gidel, D. Breysse A. Denis. Revue française de génie civil 6 (5), 789-799 (2002)

41. J. Ekblad. Road Mater. Pavement 7(3), 369-404 (2006)

42. S. Werkmeister, R. Numrich, A.R. Dawson, F. Wellner. Transportation Res. Rec. 1837, 61-70 (2003) 
43. S. Werkmeister, A.R. Dawson, F. Wellner. J. Transp. Eng. 130( 5), 665-674 (2004)

44. R. García-Rojo, H.J. Herrmann, H.J. Granul. Matter 7(2), 109-118.

45. AFNOR - EN 13286-7 - Unbound and hydraulically bound mixtures - Part 7: Cyclic load triaxial test for unbound mixtures (2004)

46. D.J. Ayres. Geotext. Geomembranes 3(2-3), 129-142 (1986)

47. G.P. Raymond. Geotext. Geomembranes 17(4), 213230 (1999)

48. T. Sussmann, K. Maser, D. Kutrubes, F. Heyns, E. Selig. Symposium on the Application of Geophysics to Engineering and Environmental Problems (2001)

49. B. Burns, G.S. Ghataora, P. Sharley. Proceedings of the First International Conference on Railway Foundations, University of Birmingham, UK, 385393 (2006)

50. G.S. Ghataora, B. Burns, M.P.N. Burrow, H.T. Evdorides. Proceedings of the First International Conference on Railway Foundations, University of Birmingham, UK, 355-366 (2006)

51. E.S. Aw. PhD Dissertation, Massachusetts Institute of Technology, USA (2007)

52. B. Indraratna, W. Salim, C. Rujikiatkamjorn. CRC Press (2011)

53. T.V. Duong, Y.J. Cui, A.M. Tang, J.C. Dupla, N. Calon, J. Canou, A. Robinet. Eng. Geol. 171, 45-58 (2014b)
54. T.V. Duong, Y.J. Cui, A.M. Tang, J.C. Dupla, J. Canou, N. Calon, A. Robinet, B. Chabot, E. De Laure Geotech. Test. J. 37(5), 1-12 (2014c)

55. A. Ridley, K. Dineen, J. Burland, P. Vaughan. Géotechnique 53 (2), 241-254 (2003)

56. Y.J. Cui, A.M. Tang, A. Mantho, E. De Laure. Geotech. Test. J. 31 (1), 95-100 (2008b)

57. D.G Toll, S.D.N. Lourenço, J. Mendes. Eng. Geol. 165, 29-37 (2012)

58. S.D.N. Lourenço, D. Gallipoli, D.G. Toll, C.E. Augarde, F.D. Evans. Can. Geotech. J. 48(2), 327 335 (2011)

59. B. Indraratna, D. Ionescu, D. Christie, R. Chowdhurry. Australian Geomechanics Journal 12, $48-61$ (1997).

60. E. Tutumluer, W. Dombrow, H. Huang. AREMA 2008 Annual Conference \& Exposition September 21-24, Salt Lake City, USA (2008)

61. T.V. Duong, Y.J. Cui, A.M. Tang, N. Calon, A. Robinet. Bull. Eng. Geol. Environ. 74(1), 259-270 (2015)

62. Y.J. Cui, F. Lamas-Lopez, V.N. Trinh, N. Calon, S. Costa D’Aguiar, J.C. Dupla, A.M. Tang, J. Canou, A. Robinet. Transportation Geotechnics 1(3), 91-105 (2014)

63. R.G. Allen, L.S. Pereira, D. Raes, M. Smith. F.A.O. 56 (1998) 